\title{
Review of achievements in the optimization coding theory for satellite channels and Earth remote sensing systems: 25 years of evolution
}

\author{
V.V. Zolotarev ${ }^{1}$, G.V. Ovechkin ${ }^{2}$, I.V. Chulkov ${ }^{1}$, P.V. Ovechkin ${ }^{2}$, S.V. Averin ${ }^{3}$, \\ D.Zh. Satibaldina ${ }^{4}$, V.T. Kao \\ ${ }^{1}$ Space Research Institute RAS, Moscow 117997, Russia \\ E-mail: zolotasd@yandex.ru \\ ${ }^{2}$ Ryazan State Radio Engineering University, Ryazan 390005, Russia \\ E-mail: g_ovechkin@mail.ru \\ ${ }^{3}$ United Radioelectronic Technologies, Moscow 111033, Russia \\ E-mail:seraverin@yandex.ru \\ ${ }^{4}$ L.N. Gumilyov Eurasian National University, Astana 010008, Kazakhstan Republic \\ E-mail: satybaldinadzh@enu.kz \\ ${ }^{5}$ Institute of Electronics, Ha Noi 122108, Vietnam \\ E-mail: caotoanryazan@gmail.com
}

\begin{abstract}
The results obtained during the 25-year evolution of the error-correction coding optimization theory (OT) and multithreshold decoding (MTD) methods, which have been created on its basis, are presented. These iterative algorithms, with each symbol correction iteration, always find decisions of strictly increasing likelihood, and can achieve optimum results that would normally require exhaustive search of all possible code words. Research results on MTDs and other error-correction methods for binary and non-binary codes used to send messages over channels with binary, symbolic errors and erasures are presented. It is shown MTDs simply decode very long codes, which are the only ones capable of supporting the effective implementation of error correction at high channel noise levels. Assessments of software implementation complexity show the advantage of MTD over other methods in terms of the number of operations per bit with comparable efficiency. It reviews the capabilities of symbolic codes, discovered by the authors, and the corresponding, simple to implement special symbolic MTD decoders, which are easier and more efficient than all other known methods of decoding non-binary codes. The methodological basis of the OT and the new paradigms for successful research into the theory and applied issues of error-correction coding are discussed. General conclusions are formulated on the study, and directions for further development of work on MTD are suggested.
\end{abstract}

Keywords: error-correction coding, multithreshold decoding, symbolic codes, self-orthogonal codes, Viterbi algorithm, flash memory, Earth Remote Sensing, highly reliable data storage, optical communications channels, codes with a directly controlled metric, divergent coding

\section{History of the subject}

In 2015, 25 years were passed from the date of defense of the dissertation (Zolotarev, 1990), where many basic results were proved for the codes that are simple from the contemporary viewpoint and were later systemized and represented within the optimization coding theory (Zolotarev, Zubarev, Ovechkin, 2016). Based on the development of the ideas of majority decoding (Massey, 1963), the optimization theory enabled us to look in an absolutely different way at the iterative error correction problem, the initial multithreshold decoding (MTD) methods of which were patented as early as 1972 (Zolotarev, 1972).

Nowadays, all main stages of the design and research of MTD algorithms are performed using special powerful optimization procedures whose effectiveness and complexity grow quickly. At the same time, the complexity of the MTD technique is a minimum and increases only linearly with a code length. Owing to an increase in the number of iterations of error correction, the MTD potential grows at a rather low complexity of the algorithm itself. At present, as compared to the 
existing methods, the MTD characteristics have already become better than those of other algorithms for practically all parameters that are interesting for communications technology ( $\mathrm{Zu}-$ barev, Ovechkin, 2008). The MTD algorithm parameters are optimized during developments and studies according to many hundreds and thousands of criteria in constructing self-orthogonal codes (SOC) with a low error propagation (EP) level, adjusting MTD algorithms (by means of selecting thresholds, weight of checks, differences in polynomials, etc.), and simulating MTD operation in different channels (Zolotarev, Zubarev, Ovechkin, 2008). This enables us to assume that the OT constitutes the basis of MTD methods and all algorithms based on them.

Below, the fundamental results concerning the efficiency and throughput of MTD algorithms developed in conformity with OT paradigms, which are compared to other known errorcorrection methods employed in Gaussian, erasure, and non-binary communications channels, are reviewed. At the end of this paper, we draw general conclusions on the situation arisen in the theory and applied investigations of error-correction coding.

\section{Gaussian channels}

Let us consider the characteristics of basic decoding algorithms operating in a Gaussian channel at the code rate $R=1 / 2$ (fig. l). In the given case, the dependences of the bit-error rate $P_{b}(e)$ of different decoding algorithms are traditionally shown in terms of function $E_{b} / N_{0}$, i.e., the level of the bit energy of a channel. The vertical line $C=1 / 2$ designates the noise level at which channel capacity $C$ is equal to the code rate: $C=R=1 / 2$. Dashed line $P_{0}$ shows error probabilities obtained without coding. Border AT indicates the limiting real up-to-date possibilities of turbo codes. However, their hardware implementation remains difficult until now because such a class of algorithms is complicated enough (Ovechkin, 2011). Curve VA:K7 illustrates the possibilities of the widespread Viterbi algorithm (VA) for short convolutional codes with the constraint length $K=7$ (Zolotarev, Ovechkin, 2004). Graph CC:VA*RS corresponds to the concatenated scheme based on the short convolutional and Reed-Solomon (RS) code (Zolotarev, Ovechkin, 2004). The min-sum decoder of the DVB-S2 low-density parity-check (LDPC) code, the length of which is 64800 bits, is characterized by curve LDPC (in 2012, this scheme was implemented at the Radio Research and Development Institute) (Ovechkin, Chikin, 2009). Graph TR defines the real potential of the decoder of CDMA2000 turbo codes with a length of 3060 bits.

In what follows, let us consider the capabilities of multithreshold algorithms (Zolotarev, Zubarev, Ovechkin, 2016). Curve MTD1 illustrates the new advancements of this algorithm, which optimally decodes a long convolutional code at a very low signal to noise ratio of $1.3 \mathrm{~dB}$ when only $1.1 \mathrm{~dB}$ is required to reach its capacity. The amount of decoder iterations is no more then $I=160$. The decoding delay is less than 6 Mbit. Naturally, the MTD algorithm is strongly simplified if the allowable noise level diminishes by only a few tenths of a decibel. For example, curve MTD2 shows the potential of this method already at 60 iterations and the decoding delay is 
less than 1 Mbit. The last decoder characterized by graph MTD3 has a very important property: opportunities of MTD for usual non-concatenated convolutional code turn out to be better than those of the very powerful (VA*RS) concatenated scheme. This decoder implements 40 iterations, and its delay is only three times as large as that of the more complex sequential concatenated scheme.

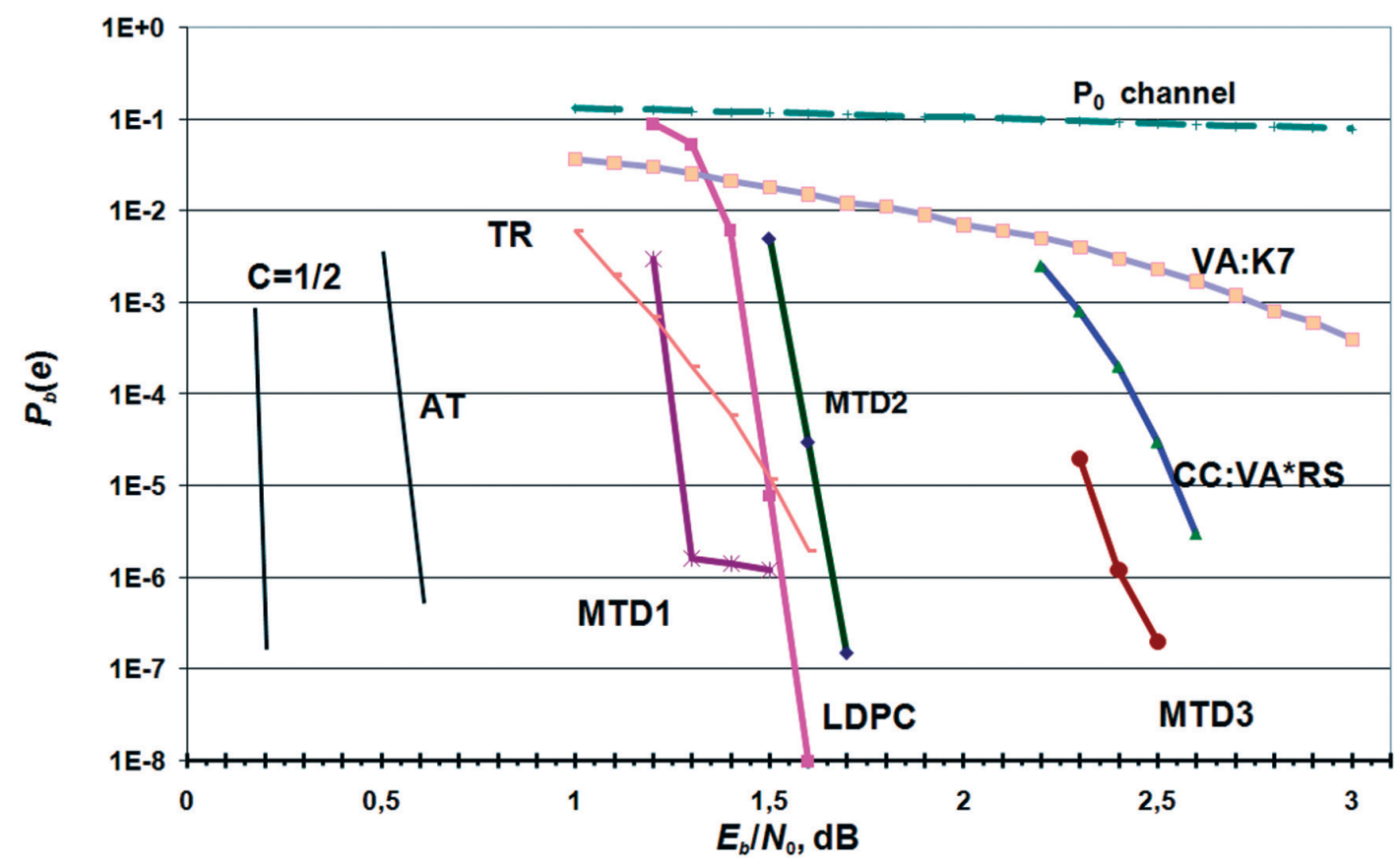

Fig. 1. Characteristics of modern basic error correction methods over Gaussian channels

Let us emphasize the main advantages of all discussed MTD methods over the other algorithms. In the region of such a high channel noise level, the VA is not competitive with MTD. The concatenated scheme with the VA and RS codes is almost at the border of fig. 1 and, consequently, does not participate in the competition of methods too. At a high noise level, the decoding effectiveness of the first MTD method is already unachievable for all known existing algorithms operating in Gaussian channels. However, the MTD development experience is evidence that its characteristics can be improved to some extent. For further substantial motion toward the Shannon limit $R=C=1 / 2$ or for attainment of other code rates, a considerable MTD modernization will be undoubtedly required (such a process is now carried out). In addition, it should be noted that, at the equal number of iterations, this procedure is simpler for MTD than, e.g., for the LDPC decoder. Moreover, in the hardware implementation of the MTD, the structure of connections between cells is much simpler as compared to other algorithms. More than $99 \%$ of an MTD is the shift-register memory, which additionally facilitates its creation and tuning. Finally, it should be indicated that, in accordance with (Zolotarev, 2009), all MTD algorithms could be implemented in hardware because they become the single-step decision scheme of instantaneous action. This leads to the fact that, by analogy with all algorithms, MTDs create decision-making delays but do not decrease the throughput of any device in which they are employed. 
Indisputably, in this case, a convolutional code should find application. It is reasonable that such a property of the convolutional MTD is called the maximum theoretical hardware throughput.

The efficient hardware implementation of the multithreshold decoder based on the ALTERA field-programmable gate array (FPGA), which was performed at the Space Research Institute of the Russian Academy of Sciences (SRI RAS), is exemplified by the working prototype depicted in fig. 2 (Zolotarev et al., 2009). For a channel throughput of no less than 1 Gbps, the given prototype exhibits high efficiency characteristics at the code rate $R=1 / 2$. The authors have no information on such efficiency levels and operating rates of fast channels, which are typical of Earth Remote Sensing (ERS) systems.

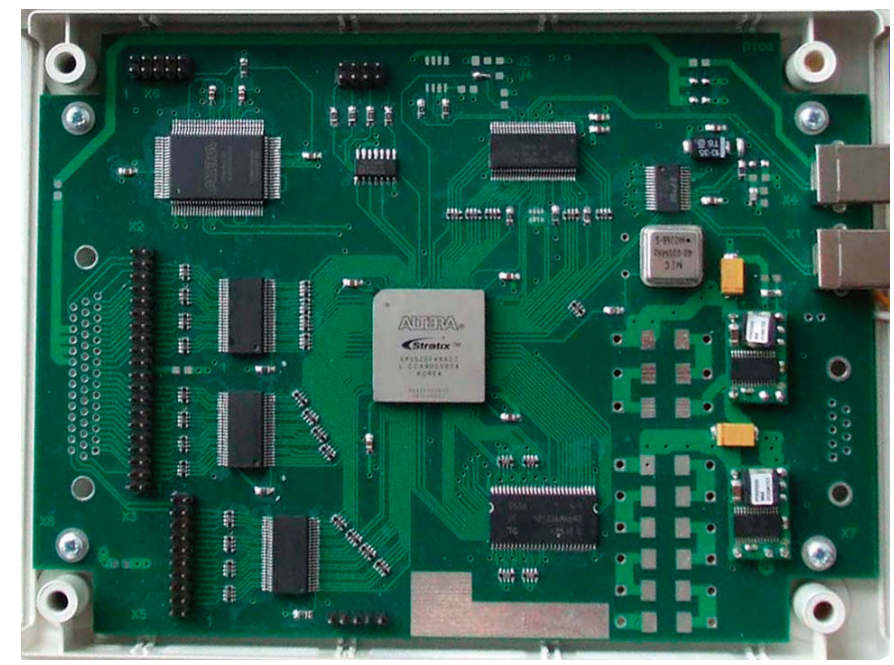

Fig. 2. MTD for space and optical channels and flesh memory

The simplicity and high throughput of MTD algorithms are illustrated well by demo programs placed at our websites www.mtdbest.ru and www.mtdbest.iki.rssi.ru. For example, the MTD algorithm installed on the PC with a Core i7 processor decodes the convolutional code with a throughput of more than $15 \mathrm{Mbps}$ at a high Gaussian channel noise level. All demo programs created for different types of decoders involve detailed instructions. Specialists can familiarize themselves with the efficiency and throughput performance of the given decoder and analyze them on the basis of new versions of demo programs with the opportunities of selecting different codes and examining their operation in MTDs.

\section{Symbolic codes}

Our scientific school has discovered symbolic codes that are now regarded to be already completely investigated (Zolotarev, Ovechkin, 2010). This fact has become highly valuable for the coding theory and different applied digital systems. As in the case of binary codes and their analogs, the MTD implementation of the discovered codes is extremely simple. At present, all 
basic estimates of decoding characteristics thereof are obtained, a large volume of simulation was performed, and the general theory of block and convolutional variants of construction was worked out in detail.

Strictly speaking, J. Massey dealt with these codes belonging to the class of majoritarily decoded non-binary codes and proved theorems 1-4 concerning them in (Massey, 1963). However, he very negatively estimated the potential of these codes in Sections 1.2, 6.2, 6.5, 6.6 and 8.2 of his book and has never returned to this subject. Nowadays, there are no any informative studies into the majority decoding of non-binary codes and, especially, publications devoted to their iterative algorithms.

Symbolic codes, the characteristics of which has been already completely investigated and developed (Zolotarev, Ovechkin, 2010), entirely solved all problems associated with highly reliable transmission and storage of digital data over many future years. They can fully replace RS codes in all possible applications, being ahead of them and other potential competitors in all comparisons of reliabilities and throughput (Ovechkin, 2009). The reason of such an advantage is the opportunity of selecting any length of the symbolic codes, which is independent of alphabet size $q$. Moreover, the most important thing is that symbolic codes permit actually optimal decoding (equivalent to total search!) with the use of majority methods even at a quite high noise level. As in the binary case, the symbolic MTD ( $q$ MTD) complexity turns out to be theoretically lowest, depending linearly on a code length.

Let us consider the capabilities of non-binary codes. The RS decoder and $q \mathrm{MTD}$ characteristics obtained at the code rate $R=1 / 2$ are presented in fig. 3. The horizontal axis incorporates the symbol-error rate calculated at different alphabet sizes $q\left(q=2^{8}=256\right.$ and $\left.2^{16}=65536\right)$ and, for convenience, the $E_{b} / N_{0}$ ratio that is valid only at $q=256$ and $R=1 / 2$. The decoder symbol-error rate $P_{d}(e)$ are plotted on the vertical axis for all values of $q$.

The graph $P_{0}$ shows the error probability in the $q$-ary non-binary symmetric channel $(q \mathrm{SC})$. Curve RS $2^{\wedge} 8$ characterizes the possibilities of the algebraic decoders for RS code with parameters $(n, k, d)(255,128,128)$, where the size of the symbol corresponds to one byte. Next dashed curve $\mathrm{RS}-\mathrm{Su} 2 \wedge 8$ corresponds to the lower estimate of the complex decoder capabilities for the same code, proposed by Sudan (Sudan, 1997). This decoder sometime corrects more errors than a half of minimum code distance $d$ but requires approximately $n$ times greater the computation volume as compared with the algebraic RS decoding methods.

Very long RS code with a symbol size of 16 bits and the length $n=65535$ symbols has the characteristics defined by graph $\mathrm{RS}^{\wedge} \wedge 16$. Its decoder is extremely complicated and, evidently, will not be the object of implementation in the nearest future. However, the demo programs for such a RS code can be copied from our websites www.mtdbest.ru and www.mtdbest.iki.rssi.ru, launched on your PC, and analyzed in full measure.

Below, let us consider the possibilities of symbolic MTDs. In the case where $q=256$ and $I=20$ iterations, the rather simple decoder of a symbolic block code with parameters $(n, k, d)$ $(8000,4000,15)$ has the characteristics designated by $\mathrm{QMTD}^{\wedge} 8$. This algorithm for the same code with $q=2^{16}$ ensures the effectiveness illustrated by curve QMTD2^16. The last graph 


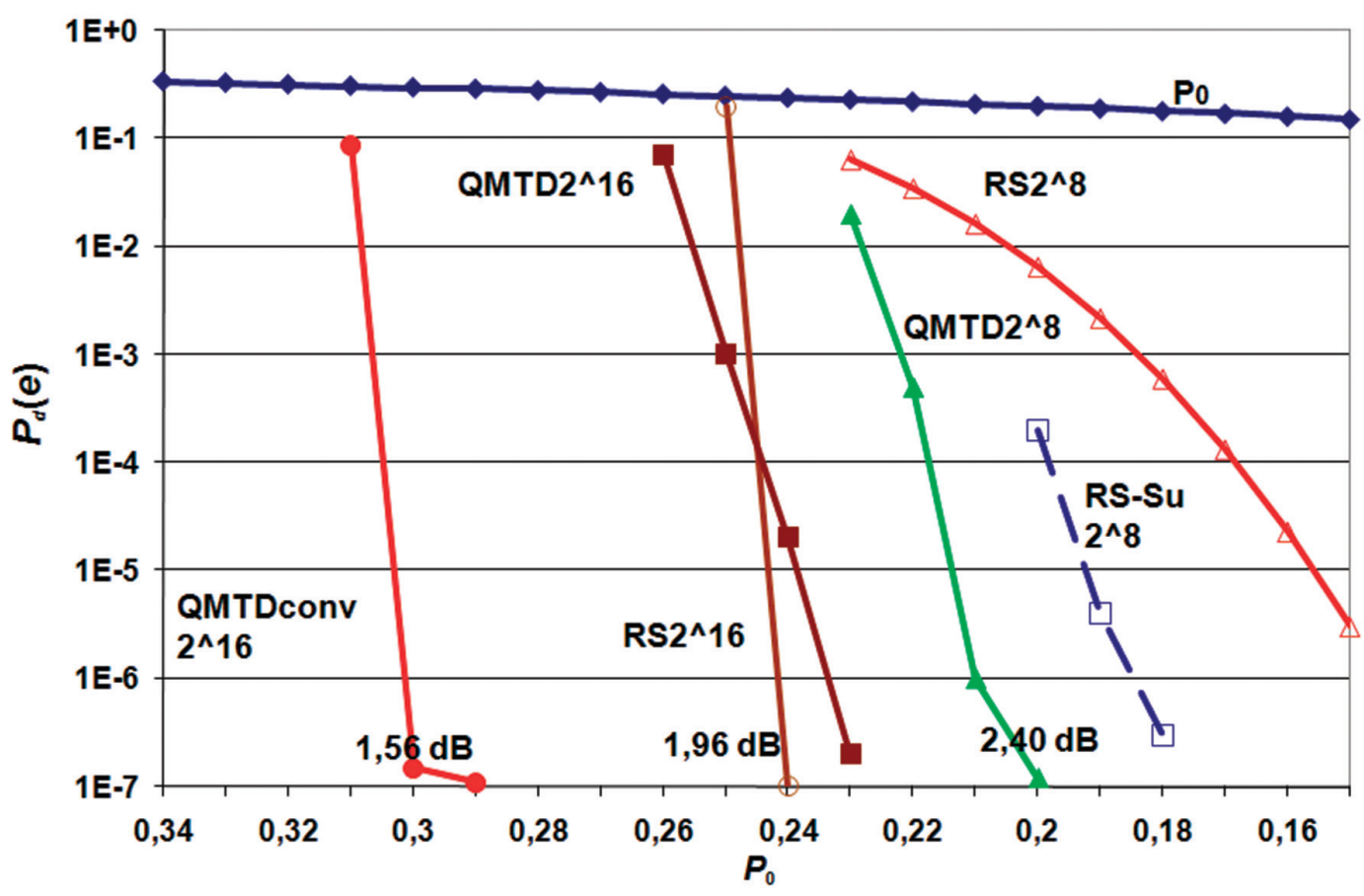

Fig. 3. Characteristics of $q M T D$ and $R S$ code decoders over $q$-ary symmetrical channel

QMTDconv $2^{\wedge} 16$ is constructed for a convolutional code with the minimum code distance $d=17$, and the constraint length $n_{A}=174000$ symbols and $q$ MTD with $I<45$ decoding iterations (decoding delay $L \leq 420000$ symbols). High capabilities of symbolic MTDs are defined by the fact that, according to the OT, its decisions, as in the binary case, tend to the decision of the optimal exhaustive search algorithm and usually reaches the optimal decoder (OD) decision even at a very high noise level, although the $q \mathrm{MTD}$ is not the OD. At $P_{d}(e)<10^{-6}$, in the lower part of graphs in fig. 3, the characteristics of all $q$ MTDs correspond to the OD level for used codes. It should be reminded that, for non-binary (and symbolic too!) codes, a Viterbi decoder cannot be constructed due to an extra complexity observed even at the constraint length $K=4-5$ symbols, especially for large values of $q$. This additionally increases the highest value of very simple and rather efficient symbolic MTDs.

In what follows, it should be noted that, at high noise levels, the good $q \mathrm{MTD}$ characteristics are achieved only if very long codes are employed. In particular, for $q \mathrm{MTD}$, the first symbolic block code with the length $n=8000$ symbols cannot be substantially shorter than its specified length at $q=256$. In going to the larger values of $q$, as in the second decoder of the same code, the decoding reliability grows to a larger extent even if the noise level becomes higher. Upon the fulfillment of these conditions, the $q$ MTD reaches quickly the OD decision, as is shown by the graphs of all three $q \mathrm{MTD}$ decoders. It is pertinent to note that, at $P_{0} \lesssim 0.3$, the third decoder ensures practically optimal decoding for a code with $R=1 / 2$. This is attained using a convolutional code, which always has the higher characteristics than those of the block code. However, its decision-making delay is appreciably larger. Moreover, the code with the very low EP level was chosen, thereby improving convergence to the optimal decision at a higher noise level. Hence, the decision-making delay of the third convolutional decoder turns out to be quite 
considerable. However, for the selected high noise levels, it value is rather acceptable. Similar efficient results for the other non-binary codes are unknown.

Let us pass to the crucial issue of the decoding complexity. For the RS code with the length $n=255$, decoder simulation demonstrated that the PC with a Core 17 processor decodes it with a throughput of about $130 \mathrm{ksps}$ (kilo symbols per second). Since the Sudan algorithm complexity is approximately $n$ times as high as that of the classical RS-code decoder, we find that, according to the graph of its lower estimate of $P_{d}(e)$, this method provides only an insignificant improvement in reliability although its complexity is very high. The second two-byte RS code $\left(q=2^{16}\right)$ with $n=65535$ symbols ensures a high reliability at $P_{0}<0.24$. However, for such a long code, the decoding complexity growing as $n^{2}$ turns out to be excessive: $0.4 \mathrm{ksps}$. Since decoding was performed using a very productive processor, it could be expected that such a decoder will be very complicated and too slow.

Let us consider symbolic MTDs. At $q=256$, the first of them is more efficient than the RS code with the Sudan decoder (Sudan, 1997). However, the complexity of the $q$ MTD software version (for the same processor) is determined by the decoding throughput equal to about $300 \mathrm{ksps}$, which is enormous without question. During one hour or even less, it is possible to accumulate the statistics containing more than a billion of symbols, i.e., up to $3 \cdot 10^{10}$ bits. Thus, MTD algorithms have really a very low complexity even at high noise levels, as was demonstrated by many publications on MTDs, including symbolic MTDs (Zolotarev, Zubarev, Ovechkin, 2016). For $q$ MTDs and RS decoders, demo programs can be copied at our websites. The complexity of the second MTD with $q=2^{16}$ is identical to that of the first because the operation algorithms and used codes of both decoders are closely coincident. They differ only in alphabet size. Therefore, their throughputs are equal. At the same time, the second decoder operates at a higher level of channel noise.

Let us consider the third decoder of a convolutional code with a particularly low EP level. Such a decoder performs the larger number of decoding iterations $(I \leq 45)$ than previous two $q$ MTDs of block codes. Its model demonstrated that the decoder throughput is $84 \mathrm{ksps}$. This is a high throughput itself, which is especially significant from the viewpoint of a high reliability and the largest possible noise level corresponding to operation of this $q \mathrm{MTD}$. In addition, it may be indicated that, in the extremely noisy channel of an ordinary PC processing typical four-byte symbols, the decoder throughput reaches $32 \cdot 84000 \approx 2.7 \mathrm{Mbps}$. Attention should be drawn to the fact that the software model of impracticable long RS decoder operated 200 times slower than the preceding one ( $\sim 0.4 \mathrm{ksps})$ at substantially smaller noise. As compared to the second block $q \mathrm{MTD}$ with approximately the same efficiency, the throughput of this long RS code decoder diminishes $\sim 750$ times. In this case, it is important that the RS decoder structure is very complex and $99 \%$ of any kind of hardware MTDs is ordinary memory. Hence, as was mentioned above, they executes only simplest operations.

At present, there are no any algorithms for non-binary codes, the capabilities of which could at least come closer to those of the given convolutional $q \mathrm{MTD}$ in efficiency and throughput. Our websites involves the demo program for the symbolic MTD at $R=19 / 20$, which operates at 
a throughput of more than $50 \mathrm{Mbps}$. The issues concerning the further improvement of symbolic MTD operation were discussed and successfully solved in (Zolotarev, Averin, 2007). This makes it possible to additionally boost their throughputs $3-5$ times.

The symbolic codes are still developed and investigated only in Russia. Papers on symbolic codes were primarily published more than 30 years ago (Zolotarev, 1984). Nowadays, there are no foreign publications intended to continue their development. We suppose that among many reasons hampering its advancement can be the specific ideology and unordinary new mathematics of the OT that did not exist in publications of foreign or Russian specialists in the coding theory. The most important new results regarding symbolic codes are reported in (Zolotarev, Zubarev, Ovechkin, 2016). These themes are now being actively developed.

The symbolic-code decoding algorithm can be used for fast recording of Earth Remote Sensing (ERS) data on various carriers. In this case, $q$ MTDs provide an especially high reliability of storage.

\section{Erasure channels}

Let us appeal to the field of coding theory that is uniquely simple and convenient for research and achievement of real results. However, before application of MTD methods (erasure channels are kept in mind), all methods exhibited extremely modest results in this field (Massey, 1963). The basic reason was undoubtedly much more attention of specialists to channels with errors. Hence, erasing-channel decoders were scarcely investigated, and their characteristics were far from those allowed by the theory. We restrict ourselves to a brief consideration of the recently obtained MTD characteristics presented in fig. 4.

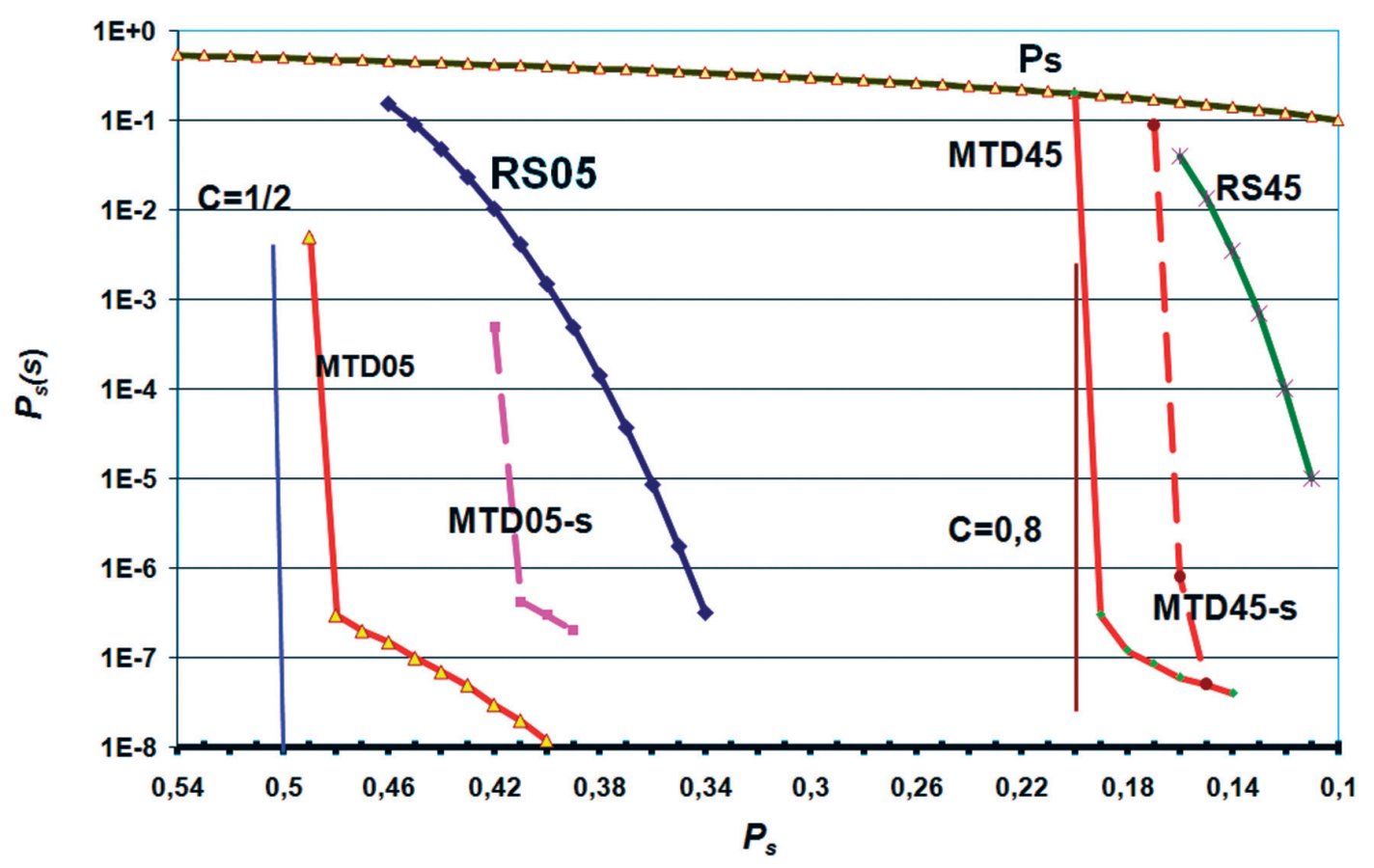

Fig. 4. Characteristics of MTD and RS code decoders over erasure channels 
For comparison, the capabilities of erasure recovery are illustrated by the graphs characterizing $\mathrm{RS}$ codes with the length $n=256$ symbols at $R=1 / 2$ (RS05) and $R=4 / 5$ (RS45).

Erasures can be recovered by means of MTD methods also (Zolotarev, Ovechkin, Shevlyakov, 2015). For this purpose, we constructed a convolutional code of rate $R=1 / 2$ with especially small grouping of errors and erasures after decoding with minimal code distance $d=21$. The decision-making delay is about 70000 information symbols, the constraint length is $n_{\mathrm{A}}=136000$ code symbols, and the number of erasure-recovery iterations does not exceed $I=90$. As is obvious from effectiveness curve MTD05, this MTD recovers the erased channel-symbol flow with erasure probability $P_{s}=0.48$ to the unrecovered symbol probability $P_{s}(s) \approx 3 \cdot 10^{-7}$. It is known that, for channels with independent erasures, the capacity is $C=1-P_{s}$, where $P_{s}$ is probability of erasure in the channel. Thus, the MTD algorithm manifests its successful operation at the ratio $R / C \approx 0.96$. This is a unique achievement for erasure-recovery algorithms. In this case, the throughput of MTD is $95 \mathrm{ksps}$. It should be noted that, as can be seen from curve RS05 at $R=1 / 2$, the RS code with such a high level of channel distortions, is inoperative. Therefore, there is no need to discuss the decoder throughput for this RS code. It is worth noting that even a small improvement in channel quality, as in the case of error correction, reduces strongly the MTD size and increases its sufficiently high throughput. In particular, at $P_{\mathrm{S}} \lesssim 0.4$, the MTD of a convolutional code, which is marked as MTD05-s in fig. 4, turns out to be 7 times faster than the first decoder due to an almost 5-fold smaller number of required iterations, and its delay diminishes 9 times. It should be emphasized that, for the second simpler MTD, the residual fraction of unrecovered symbols is many decimal orders smaller than that of the RS code.

Let us consider the possibility of erasure recovering techniques for high-rate codes with $R=4 / 5$, which are shown in the right part of fig. 4. Curve RS45 corresponds to the RS code, and the vertical line $C=0.8$ characterizes the values of the channel capacity at $P_{\mathrm{S}}=0.2$. Let us consider the potential of the MTD designated by MTD45, which restores the original digital flow with the erased symbol fraction $P_{\mathrm{S}} \lesssim 0.19$ to the level $P_{\mathrm{s}}(s)<5 \cdot 10^{-7}$ of the remaining unrecovered symbols at 180 decoding iterations with a delay of 2 million symbols (Ms). The most important thing is that, for this decoder, the ratio $R / C=0.8 / 0.81 \approx 0.988$ is valid. This is absolutely unallowable for other algorithms, including the RS code shown by curve RS45 in fig. 4. Obviously, such a closeness of parameters $R$ and $C$ inevitably leads to its greater length, as was indicated above. In this case, the MTD has a very high throughput of about $300 \mathrm{ksps}$. Moreover, when the erasedsymbol size undergoes changes, the MTD algorithm does not varies the throughput of the demo program installed on a usual PC if the alphabet size varies within 4 bytes. As a result, the decoding throughput increases to $32.300 \mathrm{ksps}=9.6 \mathrm{Msps}$. In so doing, it is impossible to specify some other methods capable of operating at such a large level of erasures.

Graph MTD45-s illustrates the opportunities of MTD algorithms at $R=4 / 5$ and a very small decrease in noise level. As in the case of the same algorithm with $R=1 / 2$, it turns out that the introduced decoding delay and the number of erasure-recovering iterations reduce 5-7 times and the throughput increases at least 3-4 times. From the viewpoint of the final reliability, this is several decimal orders better as compared to RS codes. 
The main conclusion of this section is that, in erasure channels, MTD algorithms also have no competitors in the implementation simplicity and efficiency of decoding processes.

\section{High-rate codes}

It should be emphasized that, nowadays, MTD developments have been carried out in the sufficiently wide range of code rates. In particular, all MTD properties and its advantages over the capabilities of other algorithms are kept safe at the code rate $R \approx 4 / 5$. This enables us to recommend a wide application of MTD methods (Zolotarev et al., 2009). For example, at $R=4 / 5$, high-rate MTD methods applied to optical channels were discussed in (Zolotarev et al., 2014). These results were obtained by our scientific school and foreign researchers who were consulted by our specialists. The results of Russian researchers were significantly better in terms of energy efficiency and the simplicity of MTD algorithm implementation.

The application of MTD methods can turn out to be especially useful to store large arrays of data aboard satellites and in ERS systems, where the probability of time-increasing distortions can be very high.

\section{Decoders for flash memory}

Finally, we would like to underline that the development of decoding methods for unreliable flash memory has been finished. The specificity of this problem is that the bit-error probability of the given systems should be no worse than $P_{b}(e) \sim 10^{-15}$ while the probability of unreliable bit storage can achieve the level of $10^{-3}$ or be considerably greater. Technical decisions based on MTD algorithms enabled us to solve this problem in a quite easy manner (Zolotarev, Ovechkin, Fediov, 2013). In this case, the code with MTD at $R=3 / 4$ was used, guaranteeing the necessary levels of error probability at an unreliable storage probability of $10^{-2}$.

The aforementioned information on symbolic codes and erasing and Gaussian channels also confirm the high MTD characteristics in different applications at $R \approx 0.75$ and more.

\section{On the evolution of modern coding theory}

The above-described results and a comparison between the basic methods of decoding of error-correction codes enabled us to conclude that, in the last few decades, the modern coding theory have been in the crisis stage analogous to the termination of the main development period of classical physics at the end of the nineteenth century. By then, the problems concerning blackbody radiation and photoelectron emission, which could not be solved by means of "old physics" methods, as well as the peculiarities of description of many other phenomena, had become a serious obstacle in the path of physics development because they demonstrated the serious inconsistency of scientific views on physics in our part of the Universe and its real properties. At the beginning of the twentieth century, the great physicists introduced the certain number of postulates 
and discovered new equations and laws describing our world. Many of them had become Nobel laureates.

In the last century (about 30 years ago), the coding theory offered the last good concatenated scheme with the VA and RS codes. However, afterward, even technological revolutions in the electronics circuitry could not help to indicate stable trends of the further development of coding technology. As was found, turbo codes were complicated and non-technological, and LDPC codes provide quite good results, but their implementation is impeded at very high throughput. Moreover, noticeable difficulties of these methods appeared due to their use in combination with convolutional codes. The greater crisis level characterizes the non-binary code theme, for which nothing better than short RS codes was created during 50 years of evolution.

\section{Role of the optimization theory in the research and developments of the coding theory}

The OT and its basic MTD theorem (Zolotarev, Zubarev, Ovechkin, 2016), as well as symbolic codes, EP theory, and other key results of our scientific school, have changed substantially the whole ideology and technology of decoding for satellite communications channels, ERS systems, and other projects. These new approaches decreased the complexity of the discovered theories of iterative majority algorithms as compared to other methods (such a decrease was several decimal orders) and, simultaneously, increased its energy efficiency to an optimal level, which was previously accessible only via exhaustive search methods. At all stages of symbol correction, MTD algorithms strictly converge to the optimal decision, which is guaranteed by the basic MTD theorem and in most cases, number of errors are corrected with MTD is much more the half of the code distance. For the coding theory, these factors and other important principles of development of these algorithms implemented the same functions as the new postulates of quantum mechanics. Hence, it can be assumed that the efforts of the Russian scientific school of coding theory assisted in overcoming the long crisis period of the theory. The vast ideological revolution, which changed an appreciable part of the main paradigms of the "old" coding theory, made it possible to create the conditions of its development with the help of the absolutely new principles. It can be said that its own "quantum mechanics" was formed in the coding theory. This field is still difficult for comprehension and development but very productive, as is confirmed by the results partially discussed above. At present, there are no any other ways of evolution in theory, applied methods, and decoding technologies.

\section{Optimization theory support of new coding technologies}

The new development level of the theory of MTD algorithms and the OT enable us to suppose that the current situation in information theory characterizes the transition of the errorcorrection coding theory and its technologies of the development of new decoding methods to the really new and more perfect phase of evolutional development based on the OT. Our experi- 
ence indicates that this phase ensures even now the achievements of new targets in such a sphere that are difficult for research and important for communications technique. Owing to its application, attention of specialists has already been paid to the new possibilities of coding methods, which provide effective decoders operation in extremely noisy channels at its quite moderate complexity. First of all, the use of divergent coding principles is planned to be discussed (Zolotarev, Ovechkin, 2015). This phase involves a non-concatenated gradual increase in the code distance of used codes. Another very useful trend in applied coding theory was created by joint usage of binary and symbolic MTDs with the VA, which generates the small but very effective group of methods with direct metric control. As is known, only these algorithms can measure precisely the distance between their decisions and the received message. This property defines the highest efficiency of the aforementioned method in channels with a high noise level. All other known methods do not even estimate this important decoding parameter (algebraic algorithms) or calculate only certain relative useful functions of these distances, hampering their operation and decreasing the efficiency (turbo codes, LDPC, etc.). It is this circumstance that defines the importance of the group of methods of direct metric control, which have huge prospects of development, including in joint application.

Some of these new approaches to the development of decoding algorithms have already been used to obtain the results discussed in the previous sections.

It should be emphasized that OT principles enable us to analyze the efficiency and prospects of application of the different decoders claiming to be on good positions in the competitions of error-correction methods. In particular, some researchers assume that polar codes (Arikan, 2009) known for nearly 10 years refer to new coding trends. However, a comparison between these methods and existing algorithms (Zolotarev, Ovechkin, 2016) still is evidence that this "new" direction has not been formed and found its place in terms of the efficiency and complexity of implementation. Probably, short codes with decoding according to the block VA (Zolotarev, Nazirov, 2013), e.g., with the simplest concatenated methods, would be such evident approaches, which will be efficient to the same extent and simpler in decoding than known numerous variants and modifications of polar codes. It can be expected that, in the nearest future, the real potential of the basic types of such codes manifests itself.

\section{On scientific exchange and educational process}

We understand our responsibility as world leaders for the creation of effective coding methods and will continue the development of web resources www.mtdbest.ru and www.mtdbest. iki.rssi.ru, where there are more than 400 data sections involving useful scientific, methodical, and educational materials. They also contains many demo programs for all now popular errorcorrecting algorithms of almost ten types. This hard educational work has not been done by any scientific group. Undoubtedly, our rapidly growing websites will continue to assist in developing the OT and coding technology in our country and abroad. 
The extremely significant criterion of OT recognition in the scientific world is the amount of visitors at our websites. Every year, they are visited by about 100000 people from more than 80 countries.

There are only small number of foreign papers on the subject. We are trying to help and consult foreign colleagues, but the development of decoding technology abroad is performed in the deadlock direction of "old physics". Hence, the achievements of our foreign colleagues (theoretical adaptation and the obtainment of practical results based on the OT) are more slowly implemented as compared to the Russian results (probably, the retardation can reach 715 years), although the majority of our publications are translated into English or written in English. Moreover, some of our achievements and results published more than 30 years ago, including, e.g., those concerning symbolic codes, as was indicated above, still do not have any response from other countries at all, although they are related to the fundamental scientific and applied problems of coding theory that are solved abroad in very complicated ways.

\section{Conclusions}

Optimization theory principles have made it possible to create multithreshold decoders that increase the reliability of decoding results by three or more decimal orders and, simultaneously, provide approximately the same increase in their throughputs as compared to other error-correction algorithms. These results are unique in the history of the development of digital signal processing system. OT paradigms expand the possibilities of decoding algorithms and increase the throughput and efficiency of multithreshold decoding methods and other algorithms relying on divergent and other new coding schemes.

A large number of published monographs and Russian and English manuals on the theoretical and practical questions about the OT and MTDs also contribute to the study of new promising coding methods.

At present, the OT and MTD methods turn out to be significantly more effective and simpler in comparison with all other types of decoders in the Gaussian, binary, symbolic, erasing, block, convolutional and other coding systems. Nowadays, the total number of basic coding clusters (typical combinations of the groups of parameters that are substantial for different technical applications), where MTDs are much simpler and more effective, is close to thirty and, presumably, will continue to expand rapidly.

\section{Acknowledgements}

For 45 years of the evolution of the optimization coding theory (from the date of first publications), its investigations were supported by Moscow Institute of Physics and Technology, Institute for Information Transmission Problems RAS, "Sozvezdie" Concern, Cybernetic Council 

University, Radio Research and Development Institute, Moscow Research Institute of Television, and Space Research Institute RAS. The MTD methods were tested by United Radio Electronic Technologies Corporation, Lavochkin Research and Production Association, and other companies and firms of the communications industry. The financial support of the development of MTD methods by the Russian Foundation for Basic Research (project nos. 14-07-00859, 14-07-00824, 13-07-00391, 12-07-00418, 08-07-00078, and 05-07-00024) and the grant the President of the Russian Federation (grant no. MD-639.2014.9) was really considerable.

We suppose that, as before, the number of our followers and colleagues will grow and the new areas of research and development based on the paradigm "quantum coding theory" and MTD technology will be expanded rapidly.

\section{References}

1. Zolotarev V.V., Mnogoporogovoe dekodirovanie v nedvoichnykh kanalakh (Multithreshold decoding over nonbinary channels), Voprosy radioelektroniki, seriya EVT, Moscow, 1984, Vol. 12.

2. Zolotarev V.V., Patent RF No. 2377722, 2009.

3. Zolotarev V.V., Patent SSSR No. 492878, 1972.

4. Zolotarev V.V., Suboptimal'nye algoritmy mnogoporogovogo dekodirovaniya: dis. dokt. tekhn. nauk (Suboptimal multithreshold decoding algorithms: Dr. tech. sci. thesis), Moscow, 1990. 278 p.

5. Zolotarev V.V., Nazirov R.R., Blokovaya modifikatsiya algoritma Viterbi (A Block modification of Viterbi algorithm), Proc. of 11 th Russian Conf. "Sovremennye problemy distantsionnogo zondirovaniya Zemli iz kosmosa” (Modern Problems of Earth Remote Sensing), Moscow, 2013.

6. Zolotarev V.V., Nazirov R.R., Chulkov I.V., Ovechkin G.V., Algoritmy MPD (MTD algorithms), Rossiiskii kosmos, Moscow, 2009, No. 1, pp. 60-63.

7. Zolotarev V.V., Zubarev Yu.B., Ovechkin G.V., Obzor metodov pomekhoustoichivogo kodirovaniya s ispol'zovaniem mnogoporogovykh algoritmov (Review of error correction methods with using multithreshold decoders), Tsifrovaya obrabotka signalov, Moscow, 2008, No. 1, pp. 2-11.

8. Zolotarev V.V., Ovechkin G.V., Divergentnoe kodirovanie svertochnykh kodov (Divergent decoding of convolutional codes), Proc. $13^{\text {th }}$ International Conf. "Problemy peredachi i obrabotki informatsii v setyakh $i$ sistemakh telekommunikatsii" (Problems of Data Transmission and Processing Over Communication Systems), Ryazan, 2015, pp. 27-32.

9. Zolotarev V.V., Ovechkin G.V., O sopostavlenii novykh metodov pomekhoustoichivogo kodirovaniya (About comparison of new error correction coding methods), Proc. $18^{\text {th }}$ International Conf. "Digital Signal Processing and Its Applications", Moscow, 2016, pp. 59-65.

10. Zolotarev V.V., Ovechkin G.V., Pomekhoustoichivoe kodirovanie. Metody i algoritmy. Spravochnik (Errorcorrecting coding. Methods and algorithms), Moscow: Goryachaya liniya - Telekom, 2004, $126 \mathrm{p}$.

11. Zolotarev V.V., Ovechkin G.V., Fediov V.S. Povyshenie dostovernosti khraneniya tsifrovykh dannykh na fleshpamyati (Improving reliability of data storage on flash memory), Proc. $6^{\text {th }}$ International Conf. "Kosmonavtika. Radioelektronika. Geoinformatika" (Cosmonavtic. Radioelectronic. Geoinformatic), Ryazan, 2013, pp. $201-203$.

12. Zolotarev V.V., Ovechkin G.V., Shevlyakov D.A. Uluchshenie effektivnosti mnogoporogovykh dekoderov $\mathrm{v}$ kanalakh svyazi so stiraniyami (Improving performance of multithreshold decoders in erasure channels), Fundamental'nye issledovaniya, Moscow, 2015, No. 8 (part 3), pp. 486-490.

13. Zubarev Yu.B., Ovechkin G.V., Pomekhoustoichivoe kodirovanie v tsifrovykh sistemakh peredachi dannykh (Error-correcting coding in digital communication systems), Elektrosvyaz', Moscow, 2008, No. 12, pp. 58-61.

14. Ovechkin G.V., Teoriya kaskadnogo dekodirovaniya lineinykh kodov dlya tsifrovykh radiokanalov na osnove mnogoporogovykh algoritmov: dis. doct. tekhn. nauk (Theory of concatenated decoding of linear codes based on multithreshold algorithms for digital radiochannels: Dr. tech. sci. thesis), Ryazan, 2011, $301 \mathrm{p}$.

15. Ovechkin G.V., Chikin A.V. Pomekhoustoichivost' priemnika sputnikovykh signalov DVB-S2 (Performance of DVB-S2 satellite receiver), Proc. $11^{\text {th }}$ International Conf. "Digital Signal Processing and Its Applications", Moscow, 2009, pp. 578-580.

16. Ovechkin P.V. Razrabotka algoritmov povysheniya effektivnosti nedvoichnykh mnogoporogovykh dekoderov $v$ sistemakh peredachi i khraneniya bol'shikh ob"emov informatsii: dis. kand. tekhn. nauk (Development of algorithms for improving performance of symbolic multithreshold decoders in high volume data transmission and storage systems: Cand. tech. sci. thesis), Ryazan, 2009, $131 \mathrm{p}$.

17. Arikan E., Channel Polarization: A Method for Constructing Capacity-Achieving Codes for Symmetric BinaryInput Memoryless Channels, IEEE Transactions on Information Theory, 2009, Vol. 55, No. 7, pp. 3051-3073.

18. Massey J., Threshold decoding, Cambridge, Massachusetts: M.I.T. Press, 1963.

19. Sudan M., Decoding of Reed Solomon codes beyond the error-correction bound, Journal of Complexity, 1997, Vol. 13, pp. 180-193. 
20. Zolotarev V.V., Averin S.V., Non-Binary Multithreshold Decoders with Almost Optimal Performance, 9-th ISCTA'07, UK, Ambleside, 2007.

21. Zolotarev V.V., Ovechkin G.V., Efficient Multithreshold Decoding of Nonbinary Codes, Journal of Communications Technology and Electronics, 2010, Vol. 55, No. 3, pp. 302-306.

22. Zolotarev V, Ovechkin G., Satybaldina D., Tashatov N., Adamova A., Mishin V., Efficiency multithreshold decoders for self-orthogonal block codes for optical channels, International Journal of Circuits, Systems and Signal Processing, 2014, Vol. 8, pp. 487-495.

23. Zolotarev V.V., Zubarev Yu.B., Ovechkin G.V., Optimization Coding Theory and Multithreshold Algorithms, Published in Switzerland by ITU, 2016, 158 p.

\title{
Обзор достижений оптимизационной теории для спутниковых каналов и систем Д33: 25 лет развития
}

\author{
В.В. Золотарев ${ }^{1}$, Г.В. Овечкин ${ }^{2}$, И.В. Чулков ${ }^{1}$, П.В. Овечкин ${ }^{2}$, С.В. Аверин ${ }^{3}$, \\ Д.Ж. Сатибалдина ${ }^{4}$ В.Т. Као \\ ${ }^{1}$ Институт космических исследований РАН, Москва, 117997, Россия \\ E-mail:zolotasd@yandex.ru \\ ${ }^{2}$ Рязанский государственный радиотехнический университет, Рязань, 390005, Россия \\ E-mail: g_ovechkin@mail.ru \\ ${ }^{3}$ Объединенные радиоэлектронные технологии, Москва, 111033, Россия \\ E-mail:seraverin@yandex.ru \\ ${ }^{4}$ Евразийский национальный университет им. Л.Е.Гумилева, Астана, 010008, Казахстан \\ E-mail: satybaldina_dzh@enu.kz

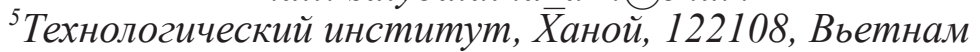 \\ E-mail: caotoanryazan@gmail.com
}

\begin{abstract}
Представлены результаты двадцатипятилетнего развития оптимизационной теории (ОТ) помехоустойчивого кодирования и методов многопорогового декодирования (МПД) самоортогональных кодов, созданных на ее основе. Данные итеративные алгоритмы при каждом изменении декодируемого символа всегда обеспечивают переход к более правдоподобному решению и могут достичь решения оптимального декодера, что обычно требует выполнения полного перебора всех возможных кодовых слов. Представлены результаты исследования эффективности МПД и других методов коррекции ошибок для двоичных и недвоичных кодов, используемых при передаче сообщений по каналам с битовыми, символьными ошибками и стираниями. Показано, что МПД легко декодируют даже очень длинные коды, которые только и способны обеспечить эффективное исправление ошибок при большом уровне шума в канале связи. Анализ вычислительной сложности показал, что МПД оказываются много проще в терминах числа операций на декодируемый бит сопоставимых по эффективности других методов исправления ошибок. Рассмотрены возможности символьных кодов, открытых авторами, и соответствующих символьных МПД, которые оказываются проще для реализации и одновременно эффективнее других методов декодирования недвоичных кодов. Обсуждается методологический базис ОТ и новые парадигмы для успешных исследований в теории и прикладных вопросах помехоустойчивого кодирования. Сформулированы основные выводы и указаны направления дальнейшего развития МПД.
\end{abstract}

Ключевые слова: помехоустойчивое кодирование, многопороговое декодирование, символьные коды, самоортогональные коды, алгоритм Витерби, флеш-память, системы дистанционного зондирования Земли, высокодостоверное хранение данных, оптические каналы связи, коды с прямым контролем метрики, дивергентное кодирование

Одобрена к печати: 08.02.2017

DOI: $10.21046 / 2070-7401-2017-14-1-9-24$

\section{Литература}

1. Золотарев В.В. Многопороговое декодирование в недвоичных каналах // Вопросы радиоэлектроники, серия ЭВТ. М., 1984. Вып. 12.

2. Золотарев В.В. Патент РФ №2377722. 2009.

3. Золотарев В.В. Патент СССР №492878. 1972. 
4. Золотарев В.В. Субоптимальные алгоритмы многопорогового декодирования: дис. д-ра техн. наук. М., $1990.278 \mathrm{c}$.

5. Золотарев В.В., Назиров Р.Р. Блоковая модификация алгоритма Витерби // Одиннадцатая Всероссийская конференция «Современные проблемы дистанционного зондирования Земли из космоса». М., 2013.

6. Золотарев В.В., Назиров Р.Р., Чулков И.В., Овечкин Г.В. Алгоритмы МПД // Российский космос. М., 2009. № 1. C. 60-63.

7. Золотарев В.В., Зубарев Ю.Б., Овечкин Г.В. Обзор методов помехоустойчивого кодирования с использованием многопороговых алгоритмов // Цифровая обработка сигналов. М., 2008. № 1. С. $2-11$.

8. Золотарев В.В., Овечкин Г.В. Дивергентное кодирование сверточных кодов // Материалы 13-й Международной научно-технической конференции «Проблемы передачи и обработки информации в сетях и системах телекоммуникаций». Рязань, 2015. С. 27-32.

9. Золотарев В.В., Овечкин Г.В. О сопоставлении новых методов помехоустойчивого кодирования // 18 Международная конференция «Цифровая обработка сигналов и ее применение». М., 2016. Т. 1. С. 59-65.

10. Золотарев В.В., Овечкин Г.В. Помехоустойчивое кодирование. Методы и алгоритмы. Справочник. М.: «Горячая линия - Телеком», 2004. 126 с.

11. Золотарев B.В., Овечкин Г.В., Федиов В.С. Повышение достоверности хранения цифровых данных на флеш-памяти // Материалы 6-й Международной научно-технической конференции «Космонавтика. Радиоэлектроника. Геоинформатика». Рязань, 2013. С. 201-203.

12. Золотарев В.В., Овечкин Г.В., Шевляков Д.А. Улучшение эффективности многопороговых декодеров в каналах связи со стираниями // Фундаментальные исследования. М., 2015. № 8 (часть 3). С. 486-490.

13. Зубарев Ю.Б., Овечкин Г.В. Помехоустойчивое кодирование в цифровых системах передачи данных // Электросвязь. М., 2008. № 12. С. 58-61.

14. Овечкин Г.В. Теория каскадного декодирования линейных кодов для цифровых радиоканалов на основе многопороговых алгоритмов: дис. докт. техн. наук. Рязань, 2011. 301 с.

15. Овечкин Г.В., Чикин А.В. Помехоустойчивость приемника спутниковых сигналов DVB-S2 // 11-я межд. конф. и выст. «Цифровая обработка сигналов и ее применение». М., 2009. С. 578-580.

16. Овечкин П.В. Разработка алгоритмов повышения эффективности недвоичных многопороговых декодеров в системах передачи и хранения больших объемов информации: дис. канд. техн. наук. Рязань, 2009. 131 с.

17. Arikan E. Channel Polarization: A Method for Constructing Capacity-Achieving Codes for Symmetric BinaryInput Memoryless Channels // IEEE Transactions on Information Theory, 2009. Vol. 55. No. 7. P. 3051-3073.

18. Massey J. Threshold decoding. M.I.T. Press, Cambridge, Massachusetts, 1963.

19. Sudan M. Decoding of Reed Solomon codes beyond the error-correction bound // Journal of Complexity. 1997. Vol. 13. P. 180-193.

20. Zolotarev V.V., Averin S.V. Non-Binary Multithreshold Decoders with Almost Optimal Performance // 9-th ISCTA'07. UK, Ambleside, 2007.

21. Zolotarev V.V., Ovechkin G.V. Efficient Multithreshold Decoding of Non-binary Codes. Journal of Communications Technology and Electronics. 2010. Vol. 55. No. 3. P. 302-306.

22. Zolotarev V., Ovechkin G., Satybaldina D., Tashatov N., Adamova A., Mishin V. Efficiency multithreshold decoders for self-orthogonal block codes for optical channels // International Journal of Circuits, Systems and Signal Processing. 2014. Vol. 8. P. 487-495.

23. Zolotarev V.V., Zubarev Yu.B., Ovechkin G.V. Optimization Coding Theory and Multithreshold Algorithms. Published in Switzerland by ITU. March 2016. 158 p. 